\title{
The Impact of Employee Empowerment on Job Engagement: Evidence from Jordan
}

\author{
Nadia Alhozi ${ }^{1}$, Nayel Al Hawamdeh ${ }^{2}$, Malek Al-Edenat ${ }^{2}$ \\ ${ }^{1}$ Engineering Studies Manager at Aqaba Development Corporation, Jordan \\ ${ }^{2}$ Faculty of Business, Business Administration Department, Tafila Technical University, At-Tafila, Jordan \\ Correspondence: Nayel Al Hawamdeh, Faculty of Business, Tafila Technical University, AT-Tafila, P.O.Box179, \\ Tafila, 66110, Jordan.
}

Received: November 27, 2020

Accepted: January 6, 2021

Online Published: January 21, 2021

doi:10.5539/ibr.v14n2p90

URL: https://doi.org/10.5539/ibr.v14n2p90

\begin{abstract}
The objective of this study was to investigate the impact of employee empowerment (i.e., structural and psychological empowerment) on job engagement (i.e., physical, emotional, and cognitive engagement). A quantitative approach was adopted in order to achieve such a study aim, and the data was collected via an online questionnaire. The sample of this study consisted of 300 employees from the Aqaba Special Economic Zone Authority (ASEZA), one of the biggest Jordanian organisations in Aqaba, with a total of 293 questionnaires retrieved and 7 excluded due to their being invalid for statistical analysis. This yielded a total of 286 accepted questionnaires, or $95.3 \%$ of the total questionnaires provided. Moreover, the Statistical Analysis Package for Social Science (SPSS) was used for data analysis, the results of which indicating that the level of implementation of employee empowerment dimensions had a medium rate amongst ASEZA's employees, as the structural empowerment was applied more than the psychological empowerment. Furthermore, the level of present job engagement dimensions also had a medium rate amongst the surveyed ASEZA employees. The results also indicated there to be a significant statistical impact by structural and psychological empowerment on physical engagement and cognitive engagement, whilst there was no significant statistical impact made by structural empowerment on emotional engagement compared to psychological empowerment, which had a significant statistical impact on it. In light of the findings of this research, ASEZA managers must pay more attention to the role of empowerment of employees in promoting work engagement, since this enhances the organisation's ability to achieve the appropriate strategy and gain a comparative advantage.
\end{abstract}

Keywords: employee empowerment, psychological empowerment, structural empowerment, job engagement, Jordan, ASEZA

\section{Introduction}

In today's competitive global environment, it takes more than following up operational success for any given business: rather, if any organisation wants to increase its profits and improve productivity, it needs to engage their people who present the best ideas, insights, and solutions; in other words, employees' empowerment is essential for the organisation (Wang et al., 2019), some researchers even suggesting that empowerment may be considered as an antecedent of engagement (Macey \& Schneider, 2008).

This study attempts to increase our knowledge on the requirement for employees to be empowered, as well as on the subsequent benefits that will arise concerning job engagement as a result. This study will also present additional information concerning employee empowerment in regard to stakeholders who are keen to aid in the realisation of empowerment amongst employees. Moreover, this study will become a source of secondary study to other researchers who are interested in employee empowerment and its impact on job engagement within their organisation; indeed, our findings will help to improve their capability to participate in future decision-making.

Considering employee empowerment and job engagement are entirely relevant to one another, and are key when it comes to enhancing employees' outcomes (Guan \& Frenkel, 2018; Guest, 2014; Yin, 2018), employees would be more willing to perform tasks that contribute to the organisation's overall success (Judge, Erez, Bono \& Thoresen, 2002) by improving empowerment levels and engagement perceptions amongst employees within a given firm (Cavus \& Gokcen, 2015). 
Empowerment is an important component of fruitful outcomes, productivity, and development within any business (Hunjra, Haq, Akbar \& Yousaf, 2011), and employee empowerment specifically is largely viewed as a persuasive practice that expands performance through the expansion of chances of investment and contribution in important decision-making processes. This entire process is centred on creating trust, inspiration, being involved in decision-making, and eliminating any limits amongst employees and top managers (Meyerson \& Dewettinck, 2012). Notably, empowerment can be defined as 'providing the employees of an organisation the authorisation to manage their day-by-day work activities' (Liden, Wayne \& Sparrowe, 2000).

The reminder of this paper is structured as follows: Section 2 discusses the literature review concerning job engagement and empowered employee, followed by Section 3, which introduces the research questions and research hypothesis. Section 4 discusses the study model, whilst Section 5 describes the research methodology that has been adopted in this research. Subsequently, Section 6 provides research results and analysis, followed by Section 7's discussion of these results. Next, Section 8 provides an overview of the research implications and recommendations, and Section 9 focuses on study limitations and future research. Finally, the references list for this research is detailed in Section 10.

\section{Literature Review}

\subsection{Job Engagement}

Engagement can be defined as 'the creation of opportunities for communication between employees largely and easily', and also expresses the establishment of an encouraging and motivating environment that meets the employees' 'desires to communicate with their work', in addition to caring for proper job performance. Indeed, as a whole, this concept expresses flexibility and continuous improvement (MacLeod, Quinn \& Clarke, 2009). It was the researcher Kahn, who explored the emergence of the concept of correlation and associated it with the term 'personal attachment'. Here, he expresses the harnessing of the capabilities of employees to complete their roles through the employee's use of the concept of physical correlation. Kahn also knew that a lack of correlation compromises an employee's role to perform emotionally and mentally (Wefald, 2008).

In his seminal paper, Kahn (1990, p.694) defined personal engagement as 'the harnessing of organisation members' selves to their work role; in engagement, people employ and express themselves physically, cognitively, and emotionally during role performances'. Notably, the concept of job engagement initially arose in the attempt to reduce staff fatigue and increase their entertainment by linking them with their work and creating a team spirit that contributes to achieving desired goals (Jeung, 2011). In this case, this concept is achieved when balancing physical needs and working conditions through successful employees' engagement (Macey \& Schneider, 2008). Indeed, a given company's success depends primarily on management, and they are the decision-makers; the more aware and conscientious management is when dealing with employees, the greater their success in achieving its goals. As for modern management, an improved thinking style that promotes efficiency and effectiveness is required, and, here, the success of this type of management is measured by the extent to which the company's employees are interested in working (Sweem, 2009).

As a pioneer in job engagement literature, Kahn (1990) suggested three dimensions of job engagement based on previous studies, these being physical engagement, emotional engagement, and cognitive engagement. Hence, we can see here that 'engagement' comprises emotional, cognitive, and behavioural components, meaning that engaged employees are naturally invested in organisations through their body, mind, and soul. However, the majority of the existing literature has addressed job engagement as one block, rather than in its three dimensions (Deepa, 2020). Notably, physical engagement refers to the physical aspect of job engagement (i.e., the physical energies exerted by employees to fulfil their tasks) (Kular, Gatenby, Rees, Soane, \& Truss, 2008); or, in the other words, it concerns the willingness of the employees to make extra efforts for the employer. Meanwhile, emotional engagement involves having good relations with supervisors and co-workers and feeling empathy for others (Abraham, 2012), whilst the cognitive dimension is seen as employees' beliefs concerning the organisation, and refers to the concentration of an individual's intellectual and absorption focused towards organisational outcomes (Rich, Lepine \& Crawford ,2010; Kahn, 1990).

\subsection{Employee Empowerment}

Empowerment is a multifaceted idea that can be characterised by individual, hierarchical, and cultural/network viewpoints (Peterson \& Zimmerman, 2004; Perkins \& Zimmerman, 1995). At the individual level, empowerment encourages the accomplishment of a person's persona; objectives through cooperation with others (Maton \& Salem, 1995; Perkins \& Zimmerman, 1995). When it comes to the representative setting, empowerment is defined as 'a type of employee association activity and concentrated on task-based inclusion and attitudinal change' (Wilkinson, 1998). 
Khalili, Sameti \& Sheybani (2016) indicate that empowerment can be defined as an administrative method by which managers and other organising members participate in influencing decision-making (i.e., the decision-making cooperation). This definition is consistent with the definition given by Baird \& Wang (2010, p. 577), who define employee empowerment as 'the delegation of power and responsibility from higher levels in the organisational hierarchy to lower level employees, especially the power to make decisions'. Meanwhile, Thamizhmanii \& Hasan (2010) states that employee empowerment concerns allowing employees the opportunity to have responsibility in decision-making. As can be seen from the above, empowerment is a well-established term and was established more than three decades ago. Extant literature additionally points out that there are two types of employee empowerment: structural empowerment and psychological empowerment (Mathieu, Gilson \& Ruddy, 2006).

Structural empowerment is defined as 'a set of activities and practices carried out by management that give power, control, and authority to their subordinates, giving them access to information, resources, support, and opportunities to learn and develop' (Chen \& Chen, 2008), whilst psychological empowerment has been defined as 'the increase in intrinsic motivation in the performance of the function, based on four concepts: the meaning of the task, competence, self-determination, and impact' (Thomas \& Velthouse, 1990). This latter type of empowerment guides the approach of the individual towards the performance of his function, and, on this note, it should be stressed that psychological empowerment is not a characteristic of personality; rather, it is a defined set of cognitions based on a certain context of work (Spreitzer, 1995).

\section{Research Question and Hypotheses}

This study is expected to contribute to the literature, particularly that concerning the Jordanian context; after all, there is an urgent need for more research to be conducted within this country (Al Hawamdeh \& Al-edenat, 2019). Notably, ASEZA is an independent institution that handles the development and management of the Aqaba Special Economic Zone and provides integrated services to investors and registered companies that have a high number of employees (Karasneh \& Al-Momani, 2020). Hence, within this study, it was important to measure the impact of employees' empowerment on job engagement with its dimensions, since it is clearly highly important for this organisation to create a model for its proper management to meet the highest level of job engagement, in turn resulting in high productivity and efficiency and ultimately impacting their growth and development. Considering the importance of employees' job engagement in the Jordanian organisations (e.g., ASEZA) and its impact in motivating employees and increasing their loyalty towards the business, the researchers constantly kept in mind the growing importance of the concept of the organisation's employees empowerment and the importance of their ownership in obtaining job engagement.

The study problem can be surmised using the following main question:

RQ1: What is the impact of Employee Empowerment (i.e., structural and psychological empowerment) on job engagement (i.e., physical engagement, emotional engagement, and cognitive engagement) in ASEZA?

This can be broken down into the following sub-questions:

What is the impact of employee empowerment (i.e., structural and psychological empowerment) on physical engagement in ASEZA?

What is the impact of employee empowerment (i.e., structural and psychological empowerment) on emotional engagement in ASEZA?

What is the impact of employee empowerment (i.e., structural and psychological empowerment) on cognitive engagement in ASEZA?

To achieve the study objective and to reach its specific goals in determining the effect of the independent variable on the dependent variable, we developed study hypotheses based on the study problem and its questions.

Our main hypothesis is that there is no statistically significant impact of employee empowerment (i.e., structural and psychological empowerment) on job engagement (i.e., physical engagement, emotional engagement, and cognitive engagement) at the level of $\alpha \leq 0.05$.

This main hypothesis is further partitioned into six hypotheses:

H0.1: There is no statistically significant impact of structural empowerment on physical engagement at the level of $\alpha \leq 0.05$.

H0.2: There is no statistically significant impact of psychological empowerment on physical engagement at the level of $\alpha \leq 0.05$. 
H0.3: There is no statistically significant impact of structural empowerment on emotional engagement at the level of $\alpha \leq 0.05$.

H0.4: There is no statistically significant impact of psychological empowerment on emotional engagement at the level of $\alpha \leq 0.05$.

H0.5: There is no statistically significant impact of structural empowerment on cognitive engagement at the level of $\alpha \leq 0.05$

H0.6: There is no statistically significant impact of psychological empowerment on cognitive engagement at the level of $\alpha \leq 0.05$.

\section{The Study Model}

Figure (1) illustrates the model adopted in this study. The independent variables'-both structural empowerment and psychological empowerment-influence on the dependent variable, job engagement (i.e., physical engagement, emotional engagement, and cognitive engagement) is depicted below.

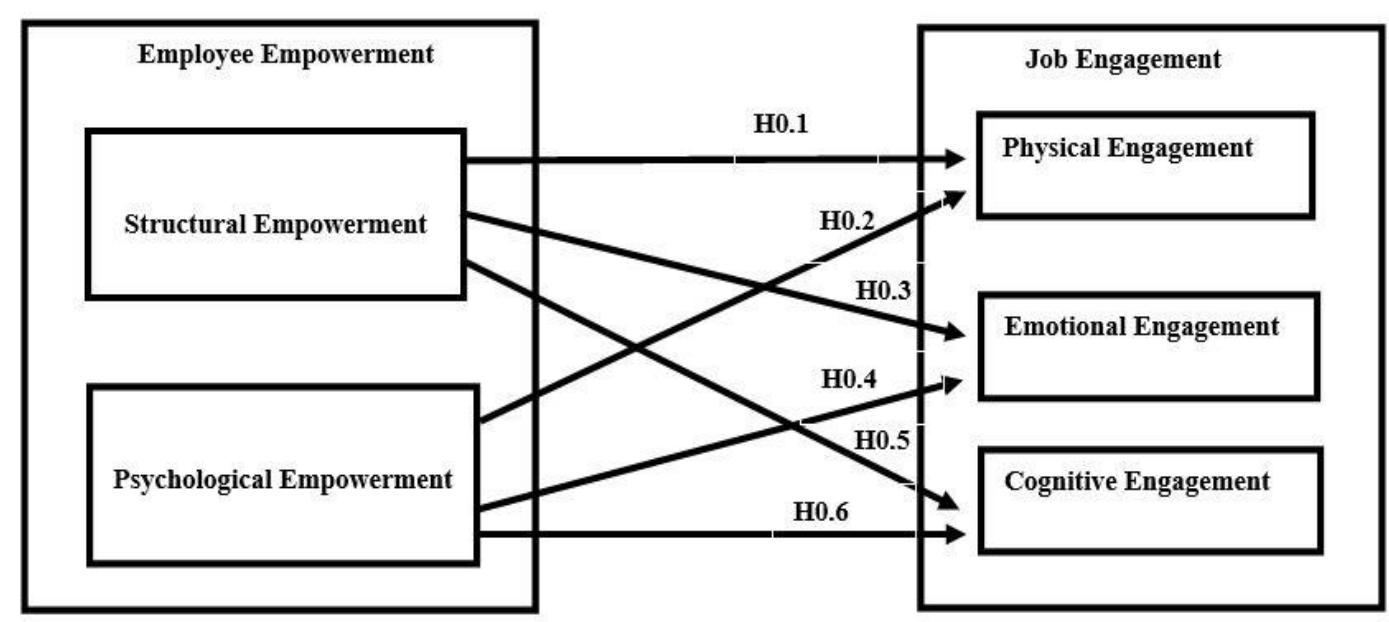

Figure 1. The Study Model

The Model Source: Prepared by the researchers to cover study variables based on the study of each. Laschinger, Finegan, Shamian, \& Wilk, (2001), Rich et al., (2010), Spreitzer (1995).

\section{Methodology}

\subsection{Study Design}

The deductive measure was used as a general approach, and, more specifically, the quantitative method of a questionnaire was used for gathering data from the sample population. Further, the program used for measuring the data was the Statistical Package for Social Science (Version 26).

\subsection{Questionnaire Design}

The data was obtained via the development of a special questionnaire for the subject of this study. By referring to the previous studies in this field included in the table with the aim of covering all aspects addressed by the theoretical framework, questions, and hypotheses on which the study was based, Table 1 demonstrates the distribution of the paragraphs of each element separately and their number, as shown in the questionnaire. Moreover, the responses of the study sample were distributed according to the Likert Quintile Scale, which indicates the extent of the respondent's agreement with the questionnaire paragraphs (i.e., 'strongly agree' $=5$, 'agree' $=4$, 'neutral' $=3$, 'disagree $=2$, and 'strongly disagree' $=1$ ). 
Table 1. The Source of Measurement Items

\begin{tabular}{lcc}
\hline Variable & Items & Reference \\
\hline Structural Empowerment & 19 & Laschinger et al., (2001) \\
Psychological Empowerment & 12 & Spreitzer (1995) \\
Physical Engagement & 6 & Rich et al., (2010) \\
Emotional Engagement & 6 & Rich et al., (2010) \\
Cognitive Engagement & 6 & Rich et al., (2010) \\
\hline
\end{tabular}

\subsection{Data Collection Procedures}

Google Forms was used to collect data from a sample of employees (both men and women and spanning from ASEZA). The sample type was purposive, and it comprised a high number of employees (roughly 2,047) based in the human resource department in ASEZA. The sample consisted of 300 employees from four various jobs . A total of 293 questionnaires retrieved and 7 excluded due to their being invalid for statistical analysis. This yielded a total of 286 accepted questionnaires, or $95.3 \%$ of the total questionnaires provided, as can be seen in Table 2.

Table 2. Profiles of Respondents

\begin{tabular}{cccc}
\hline Variable & Level / Category & Number & Percentage \% \\
\hline Gender & Male & 214 & $74.8 \%$ \\
& Female & 72 & $25.2 \%$ \\
Age & Under 30 years & 1 & $0.3 \%$ \\
& $30-$ 39 years & 47 & $16.4 \%$ \\
& $40-49$ years & 157 & $54.9 \%$ \\
Education & 50 years or more & 81 & $28.3 \%$ \\
& Diploma or below & 42 & $14.7 \%$ \\
& Bachelor & 181 & $63.3 \%$ \\
Job Position & Master's degree & 55 & $19.2 \%$ \\
& PhD degree & $8.8 \%$ \\
& Accountant & 21 & $7.3 \%$ \\
Years of Experience & Programmer & 11 & $3.8 \%$ \\
& Frontline employee & 146 & $51.0 \%$ \\
& Specialist & 108 & $37.8 \%$ \\
Less than 5 & 4 & $1.4 \%$ \\
Total of accepted questionnaires from participants & 33 & $11.5 \%$ \\
& 5- less 10 & 69 & $24.1 \%$ \\
\end{tabular}

\subsection{Reliability and Normality}

The Cronbach's Alpha was used for internal consistency so as to ensure that the questionnaire was valid as a data collection tool for the current study, its coefficient notably being used to measure the level of internal consistency of the resolution of the paragraphs. This can be seen in Table 3.

Reliability was tested using the Cronbach-Alpha coefficient to determine the degree of consistency and internal stability in the scale used to measure the variables of the hypotheses. According to Hair, Black, Babi, Anderson \& Tatham (2014), if the Cronbach-Alpha coefficient is more than 60\%, then the analysis and interpretation of the data is reliable.

Table 3. Internal consistency coefficients (Cronbach Alpha)

\begin{tabular}{cc}
\hline Variables & Stability Coefficient \\
\hline Structural Empowerment & .826 \\
Psychological Empowerment & .908 \\
Physical Engagement & .820 \\
Emotional Engagement & .899 \\
Cognitive Engagement & .859 \\
\hline
\end{tabular}

As can be seen in Table 3, the security coefficients of the variables were higher than $60 \%$, which shows internal consistency between the paragraphs. Further, $94.8 \%$, which is higher than $60 \%$, also indicates inside consistency 
amongst all the passages, which affirms the legitimacy of the survey in theory tested (Sekaran \& Bougie, 2016). As can be seen in Table 4, the dependent variable (as well as all its dimensions) follow the normal distribution, since the values of Kolmogorf-Smirnov Z $(0.056,0.074)$ are less than 1.96 . Further, the significant Sig for each of them was less than 0.05 , which shows the distribution for the questions was normal.

Table 4. Normal Distribution of Data

\begin{tabular}{llcc}
\hline \multicolumn{1}{c}{ Normal Distribution of Data } & $\begin{array}{c}\text { Employee } \\
\text { Empowerment }\end{array}$ & Job Engagement \\
\hline $\mathrm{N}$ & & 286 & 286 \\
Normal Parameters & Mean & 3.4734 & 3.4910 \\
& Std. Deviation & .62385 & .64138 \\
Test Statistic & & .056 & .074 \\
Asymp. Sig. (2-tailed) & & $.000^{\mathrm{c}}$ & $.001^{\mathrm{c}}$ \\
\hline
\end{tabular}

\section{Analysis and Results}

\subsection{Level of Employee Empowerment and Job Engagement at ASEZA}

Table 5 shows the mathematical averages of respondents' answers to the employee empowerment questionnaire. The first variable is structural empowerment, which boasted an average of 3.66 and a medium rating. Finally, psychological empowerment had an average of 3.28 and a medium rating. This indicates that the level of employee empowerment's dimensions' implementation was medium amongst the surveyed ASEZA employees.

Table 5. The arithmetical averages and standard deviations of Independent variables (Employee Empowerment

\begin{tabular}{ccc}
\hline Variables & Mean & Standard Deviation \\
\hline Structural Empowerment & 3.6622 & .60585 \\
Psychological Empowerment & 3.2846 & .91336 \\
Total & $\mathbf{3 . 4 7 3 4}$ & Medium \\
\hline
\end{tabular}

Table 6 shows the mathematical averages of the respondents' answers to the survey. The first variable is cognitive engagement with an average of 3.63 and a medium rating, the second being physical engagement, with an average of 3.56 and a medium rating. Finally, emotional engagement has an average of 3.28 and a medium rating. It indicates that the level of job engagement dimensions was medium amongst surveyed ASEZA's employees.

Table 6. The arithmetical averages and standard deviations of Independent variables (Job Engagement)

\begin{tabular}{ccc}
\hline Variables & Mean & Standard Deviation \\
\hline Physical Engagement & 3.5586 & .69005 \\
Emotional Engagement & 3.2839 & .80295 \\
Cognitive Engagement & 3.6307 & .69977 \\
Total & $\mathbf{3 . 4 9 1 0}$ & medium \\
\hline
\end{tabular}

\subsection{Hypothesis Testing}

\subsubsection{Testing the First and second Hypothesis}

Our first hypothesis is that there is no statistically significant impact of structural empowerment on physical engagement at the level of $\alpha \leq 0.05$, whilst our second is that there is no statistically significant impact of psychological empowerment on physical engagement at the level of $\alpha \leq 0.05$.

Notably, a multiple regression test was conducted in order to investigate the impact of employee empowerment (i.e., structural empowerment and psychological empowerment) on physical engagement, as shown in the following tables.

Table 7. (Model Summary)

\begin{tabular}{ccccc}
\hline Model & $\mathbf{R}$ & $\mathbf{R}^{\mathbf{2}}$ & Adjusted R Square & Std. Error of the Estimate \\
\hline 1 & $.652^{\mathrm{a}}$ & .425 & .421 & .52527 \\
\hline
\end{tabular}


Table 7 indicates that the value of the correlation coefficient of employee empowerment and the variable (i.e., physical engagement) was $65.2 \%$, whilst the value of the coefficient of determination $\left(\mathrm{R}^{2}\right)$ is 0.425 . Hence, $42.5 \%$ of the total variance is detailed in the model, whilst the rest is explained by other factors (Hair et al., 2014).

Table 8. Analysis of variance (ANOVA)

\begin{tabular}{|c|c|c|c|c|c|c|}
\hline \multicolumn{2}{|c|}{ Model } & $\begin{array}{c}\text { Sum of } \\
\text { Squares }\end{array}$ & df & Mean Square & $\mathbf{F}$ & Sig. \\
\hline \multirow[t]{3}{*}{1} & Regression & 57.623 & 2 & 28.812 & 104.422 & $.000^{b}$ \\
\hline & Residual & 78.083 & 283 & .276 & & \\
\hline & Total & 135.707 & 285 & & & \\
\hline
\end{tabular}

Table 8 indicates that the value of $\mathrm{F}$ is 104.422 , as well as that the statistical significance level is $(0.00)$ and is thus less than (0.05).

Table 9. Table of Coefficient

\begin{tabular}{lccccc}
\hline \multicolumn{1}{c}{ Element } & B & Std. Error & Beta & T & Sig. \\
\hline (Constant) & 1.456 & .191 & & 7.608 & .000 \\
Structural Empowerment & .240 & .068 & .211 & 3.515 & .001 \\
Psychological Empowerment & .372 & .045 & .493 & 8.207 & .000 \\
\hline
\end{tabular}

Table 9 shows the results of the coefficients measuring the impact of employee empowerment on physical engagement, and indicates that the calculated $t$ values for structural empowerment and psychological empowerment were 3.515 and 8.207 respectively. Further, the level of significance of $t$ sig was $0.001,0.00$. The table additionally shows there to be a statistically significant impact at $(\alpha \leq 0.05)$ of structural empowerment and psychological empowerment on physical engagement.

Hence, with all of the above taken into account, the null hypotheses are rejected and the alternative hypotheses accepted. There was a notable impact of employee empowerment (i.e., structural and psychological empowerment) on physical engagement at a significant level $(\alpha \leq 0.05)$.

\subsubsection{Testing the Third and Fourth Hypothesis}

Our third hypothesis was that there is no statistically significant impact of structural empowerment on emotional engagement at the level of $\alpha \leq 0.05$, whilst our fourth was that there is no statistically significant impact of psychological empowerment on emotional engagement at the level of $\alpha \leq 0.05$.

In order to investigate the impact of employee empowerment (i.e., structural and psychological empowerment on emotional engagement, the multiple regression test was employed (as can be seen in the following tables).

Table 10. (Model Summary)

\begin{tabular}{ccccc}
\hline Model & $\mathbf{R}$ & $\mathbf{R}^{\mathbf{2}}$ & Adjusted R Square & Std. Error of the Estimate \\
\hline 1 & $.770^{\mathrm{a}}$ & .593 & .590 & .51409 \\
\hline
\end{tabular}

As can be seen in Table 10, the value of the coefficient of employee empowerment and the variable (i.e., emotional engagement) was $77.0 \%$, whilst the value of the coefficient of determination $\left(\mathrm{R}^{2}\right)$ is 0.593 . Hence, $59.3 \%$ of the total variance is explained by the model, the remainder being explained by other factors (Hair et al., 2014).

Table 11. Analysis of variance (ANOVA)

\begin{tabular}{|c|c|c|c|c|c|c|}
\hline \multicolumn{2}{|c|}{ Model } & \multirow{2}{*}{$\begin{array}{l}\begin{array}{l}\text { Sum } \\
\text { Squares }\end{array} \\
108.953\end{array}$} & \multirow{2}{*}{$\begin{array}{r}\mathbf{d f} \\
2\end{array}$} & \multirow{2}{*}{$\begin{array}{c}\text { Mean Square } \\
54.477\end{array}$} & \multirow{2}{*}{$\begin{array}{l}\text { F } \\
206.127\end{array}$} & \multirow{2}{*}{$\begin{array}{l}\text { Sig. } \\
.000^{\mathrm{b}}\end{array}$} \\
\hline 1 & Regression & & & & & \\
\hline & Residual & 74.793 & 283 & .264 & & \\
\hline & Total & 183.746 & 285 & & & \\
\hline
\end{tabular}


As can be seen in Table 11, the value of $\mathrm{F}$ is 206.127 and the statistical significance level is 0.00 (and is thus less than 0.05); hence, the null hypothesis is rejected and the alternative hypothesis accepted. Further, there was an observed impact of employee empowerment (i.e., structural and psychological empowerment) on emotional engagement at a significant level $(\alpha \leq 0.05)$.

Table 12. Table of Coefficient

\begin{tabular}{lccccc}
\hline \multicolumn{1}{c}{ Element } & B & Std. Error & Beta & T & Sig. \\
\hline (Constant) & .813 & .187 & & 4.340 & .000 \\
Structural Empowerment & .115 & .067 & .087 & 1.718 & .087 \\
Psychological Empowerment & .624 & .044 & .710 & 14.059 & .000 \\
\hline
\end{tabular}

Table 12 details the results of the coefficients for the impact of employee empowerment on emotional engagement, as well as the calculated $t$ values for structural and psychological empowerment (i.e., 1.718 and 14.059 respectively). The level of significance of $t$ sig was notably $0.087,0.00$.

Hence, the alternative hypothesis (H0.3) is accepted, meaning there is no significant impact of structural empowerment on emotional engagement at the level of $\alpha \leq 0.05$; meanwhile, the null hypothesis (H0.4) is rejected. The acceptance of the former hypothesis suggests there to be an impact by psychological empowerment on emotional engagement at a significant level $(\alpha \leq 0.05)$.

\subsubsection{Testing the Fifth and Sixth Hypothesis}

Our fifth hypothesis stated there to be no statistically significant impact of structural empowerment on cognitive engagement at the level of $\alpha \leq 0.05$, whilst our sixth hypothesis stated there was no statistically significant impact of psychological empowerment on cognitive engagement at the level of $\alpha \leq 0.05$

Notably, in order to investigate the impact of employee empowerment (i.e., structural and psychological empowerment) on cognitive engagement, the multiple regression test was used, as can be seen below.

Table 13. (Model Summary)

\begin{tabular}{ccccc}
\hline Model & $\mathbf{R}$ & $\mathbf{R}^{\mathbf{2}}$ & Adjusted R Square & Std. Error of the Estimate \\
\hline 1 & $.480^{\mathrm{a}}$ & .230 & .225 & .61613 \\
\hline
\end{tabular}

Table 13 indicates the value of the coefficient of employee empowerment and the variable cognitive engagement to be $48.0 \%$, whilst the value of the coefficient of determination $\left(\mathrm{R}^{2}\right)$ is 0.230 . Hence, $23.0 \%$ of the total variance is explained by the model, the rest being explained by other factors.

Table 14. Analysis of variance (ANOVA)

\begin{tabular}{llccccc}
\hline & Model & $\begin{array}{c}\text { Sum of } \\
\text { Squares }\end{array}$ & df & Mean Square & F & Sig. \\
\hline 1 & Regression & 32.019 & 2 & 16.009 & 42.173 & $.000^{\mathrm{b}}$ \\
& Residual & 107.050 & 283 & .380 & & \\
& Total & 139.069 & 285 & & & \\
\hline
\end{tabular}

Table 14 the value of $\mathrm{F}$ to be 42.173 and the statistical significance level to be 0.00 (and thus less than 0.05 ).

Table 15. Table of Coefficient

\begin{tabular}{cccccc}
\hline Element & B & Std. Error & Beta & T & Sig. \\
\hline (Constant) & 1.937 & .225 & & 8.620 & .000 \\
Structural Empowerment & .252 & .081 & .218 & 3.126 & .002 \\
Psychological Empowerment & .234 & .054 & .306 & 4.379 & .000 \\
\hline
\end{tabular}

Table 15 shows the results of the coefficients in terms of employee empowerment's impact on cognitive engagement. The table shows the calculated $t$ values for structural and psychological empowerment to be 3.126 
and 4.379 respectively, whilst the level of significance of $\mathrm{t}$ sig was $0.002,0.00$. The table also shows that there was a statistically significant impact at $\alpha \leq 0.05$ in terms of structural and psychological empowerment on cognitive engagement.

Hence, the null hypotheses are rejected and the alternative hypotheses accepted: there was an impact of employee empowerment (i.e., structural and psychological empowerment) on cognitive engagement at a significant level $(\alpha \leq 0.05)$.

\section{Discussion}

The results garnered indicated the mathematical averages of the respondents' answers to the Employee Empowerment survey. Here, the first variable was structural empowerment with an average of 3.66 and a medium rating, whilst psychological empowerment boasted an average of 3.28 and a medium rating. This indicates that the level of application of Employee Empowerment dimensions was medium amongst the surveyed ASEZA organisations.

Further to this, the result showed the mathematical averages of the respondents' answers to Job Engagement to be 3.63 and a medium rating and 3.56 and a medium rating for cognitive engagement and physical engagement respectively. Finally, emotional engagement had an average of 3.28 and a medium rating, which indicates that the level of job engagement dimensions is medium amongst the surveyed ASEZA organisations.

The results garnered here led to the rejection of the first and second hypotheses, whilst the alternative hypotheses were accepted. Thus, there an impact of employee empowerment (i.e., structural and psychological empowerment could be found on physical engagement.

Furthermore, the findings of this research are consistent with the current literature, which has linked the empowerment of employees with their job engagement (e.g., Sharma \& Singh, 2018; Jose \& Mampilly, 2014; Albrecht \& Andreetta, 2011). Moreover, this study is considered to be one of the first empirical studies investigating the impact of the two kinds of employee empowerment on the three job engagement dimensions.

Moreover, the findings garnered from this study are congruent with the conclusion that meaningful work and psychological meaningfulness highly influence employee engagement (Malik, Nawab, Naeem \& Danish, 2010; Kahn, 1990), which links job resources, support, and feedback to organisational outcomes through engagement (Schaufeli \& Bakker, 2004).

The analysis of the third hypothesis reveals there to be no statistical impact of structural empowerment on emotional engagement, which is not consistent with previous studies' results (e.g., Amor, Vázquez \& Faíña, 2020; Laschinger, Wilk, Cho \& Greco, 2009), which suggest structural empowerment to be a significant predictor of job engagement. However, analysis of the fourth hypothesis indicates there to be a statistically significant impact of psychological empowerment on emotional engagement - a finding that provides additional support for recent studies that have suggested psychological empowerment as a motivational factor for job engagement (Joo, Bozer, \& Ready, 2019).

Finally, the result of the fifth and sixth hypotheses show there to be a statistically significant impact of structural empowerment and psychological empowerment on cognitive engagement, as is consistent with the study of Greco, Laschinger, \& Wong (2006), which concludes that when an employee receives a high level of empowerment, this leads to increased job engagement.

\section{Implications and Recommendations}

This study contributes to the literature of human resources management by showing the impact of employee empowerment on job engagement in developing countries (e.g., Jordan); further, this study provides a set of managerial implications for achieving a better understanding of the influential factors that support job engagement. The empirical evidence of this research reveals that in ASEZA, employee empowerment and job engagement impact several dimensions within the workplace, including structural empowerment; this can be explained by the fact that there are many departments and heads of departments who are looking to be promoted and connect their engagement with the structural empowerment via promotion. Moreover, the employees in this organisation require a lot of care psychologically, as per the results, since structural empowerment is massively influential in motivating them and, in turn, increasing their job engagement.

This research provides several recommendations for the current study, according to the results of the study. One recommendation of the current research is to increase the application of the study variables, as well as to prioritise identifying employee empowerment and the necessity of its application in the work processes to improve employees' job engagement. Based on the first and second result of descriptive statistics, this research 
also recommends maintaining the current level of employee empowerment by maintaining incentives and improving them whenever possible; this can also be done by seeking out more compensation processes to reach a higher level of engagement and loyalty amongst employees. Further, based on the second result of descriptive statistics, this study stresses the importance of implementing employee empowerment that increases the organisation's ability to achieve the appropriate strategy by knowing how to motivate their employees - especially leaders from senior and middle managers - to be more flexible in facing environmental challenges. Further, on the grounds of the sixth and eighth hypothesis results, it is advised that organisations' management should increase the communications between their employees in different levels to ensure each employee possesses enough information required to do his job properly, in turn increasing the likelihood of strong job engagement. Based on all of the results collectively, this study recommends the organisations' management to ensure the independence of their employees and provide them with the autonomy to involve at work and take decisions related to their responsibilities.

\section{Limitations and Future Research}

Through descriptive analysis and the emergence of a mean application of these variables (and on the grounds of previous studies with a similar result), we conclude that more studies should be conducted within organisations possessing a sample size larger than this study. In addition, expanding the level of employee engagement will enrich future studies and obtain accurate results on the impact of employee empowerment on employee engagement. This study thus concludes there to be a strong need to initiate further research involving various levels of employees in organisations distributed in many cities throughout Jordan. Further, this study also recommends focus being paid to empowering employees and its relationship with job engagement within more dimensions (e.g., loyalty; commitment), since it is important to ensure job engagement in each employee.

Whilst this research offers novel contributions to the understanding of the impact of employee empowerment on job engagement, it is still subject to some limitations - mainly concerning the generalisability of the results. This study was conducted in Jordan (a rich developing country), and, more specifically, in the ASEZA, and, whilst this context may undermine the generalisability of this research, it allowed for the controlling of cultural and industrial differences in the analysis. Therefore, conducting future research in other service organisations or public organisations in Jordan (or other countries) may lead to a more comprehensive understanding of the impact of employee empowerment on job engagement. Further, the study was prepared in light of the emerging Coronavirus pandemic, and so the data was collected during the spread of this pandemic. Therefore, it was not possible to add more participants, especially during lockdown periods - the factor that ultimately led us to the employment of one method of data collection (i.e., online questionnaires).

\section{References}

Abraham, S. (2012). Job satisfaction as an antecedent to employee engagement. sies Journal of Management, $8(2)$.

Al Hawamdeh, N., \& Al-edenat, M. (2019). Determinants of Barriers to Knowledge Sharing in the Jordanian Hospitality Industry. International Business Research, 12(7), 121-132. https://doi.org/10.5539/ibr.v12n7p121

Albrecht, S. L., \& Andreetta, M. (2011). The influence of empowering leadership, empowerment and engagement on affective commitment and turnover intentions in community health service workers. Leadership in health services. https://doi.org/10.1108/17511871111151126

Amor, A. M., Vázquez, J. P. A., \& Faíña, J. A. (2020). Transformational leadership and work engagement: Exploring the mediating role of structural empowerment. European Management Journal, 38(1), 169-178. https://doi.org/10.1016/j.emj.2019.06.007

Baird, K., \& Wang, H. (2010). Employee empowerment: Extent of adoption and influential factors. Personnel Review. https://doi.org/10.1108/00483481011064154

Cavus, M. F., \& Gokcen, A. (2015). Psychological capital: Definition, components and effects. Journal of Education, Society and Behavioural Science, 244-255. https://doi.org/10.9734/BJESBS/2015/12574

Chen, H. F., \& Chen, Y. C. (2008). The impact of work redesign and psychological empowerment on organizational commitment in a changing environment: An example from Taiwan's state-owned enterprises. Public Personnel Management, 37(3), 279-302. https://doi.org/10.1177/009102600803700302

Deepa, S. M. (2020). The effects of organizational justice dimensions on facets of job engagement. International Journal of Organization Theory \& Behavior. https://doi.org/10.1108/IJOTB-05-2019-0066 
Greco, P., Laschinger, H. K. S., \& Wong, C. (2006). Leader empowering behaviours, staff nurse empowerment and work engagement/burnout. Nursing Leadership, 19(4), 41-56. https://doi.org/10.12927/cjnl.2006.18599

Guan, X., \& Frenkel, S. (2018). How HR practice, work engagement and job crafting influence employee performance. Chinese Management Studies. https://doi.org/10.1108/CMS-11-2017-0328

Guest, D. (2014). Employee engagement: a sceptical analysis. Journal of Organizational Effectiveness: People and Performance. https://doi.org/10.1108/JOEPP-04-2014-0017

Hair, J. F., Black, W. C., Babin, B. J., \& Anderson, R. E. (2014). Multivariate data analysis: Pearson new international edition. Essex: Pearson Education Limited.

Hunjra, A. I., Ul Haq, N., Akbar, S. W., \& Yousaf, M. (2011). Impact of employee empowerment on job satisfaction: an empirical analysis of Pakistani service industry. Interdisciplinary Journal of Contemporary Research in Business, 2(11), 680.

Jeung, C. W. (2011). The concept of employee engagement: A comprehensive review from a positive organizational behavior perspective. Performance Improvement Quarterly, 24(2), 49-69. https://doi.org/10.1002/piq.20110

Joo, B. K., Lim, D. H., \& Kim, S. (2016). Enhancing work engagement: the roles of psychological capital, authentic leadership, and work empowerment. The Leadership \& Organization Development Journal, 37(8), 1117-1134. https://doi.org/10.1108/LODJ-01-2015-0005

Jose, G., \& Mampilly, S. R. (2014). Psychological empowerment as a predictor of employee engagement: An empirical attestation. Global Business Review, 15(1), 93-104. https://doi.org/10.1177/0972150913515589

Judge, T. A., Erez, A., Bono, J. E., \& Thoresen, C. J. (2002). Are measures of self-esteem, neuroticism, locus of control, and generalized self-efficacy indicators of a common core construct? Journal of personality and social psychology, 83(3), 693. https://doi.org/10.1037/0022-3514.83.3.693

Kahn, W. A. (1990). Psychological conditions of personal engagement and disengagement at work. Academy of management journal, 33(4), 692-724. https://doi.org/10.5465/256287

Karasneh, A. A. F., \& Al-Momani, E. A. (2020). The influence of emotional intelligence on leadership styles: A profile of executives in ASEZA organization. Journal of Public Affairs, 20(3), e2069. https://doi.org/10.1002/pa.2069

Khalili, H., Sameti, A., \& Sheybani, H. (2016). A study on the effect of empowerment on customer orientation of employees. Global Business Review, 17(1), 38-50. https://doi.org/10.1177/0972150915610674

Kular, S., Gatenby, M., Rees, C., Soane, E., \& Truss, K. (2008). Employee engagement: A literature review.

Laschinger, H. K. S., Finegan, J., Shamian, J., \& Wilk, P. (2001). Impact of structural and psychological empowerment on job strain in nursing work settings: expanding Kanter's model. JONA: The Journal of Nursing Administration, 31(5), 260-272. https://doi.org/10.1097/00005110-200105000-00006

LASCHINGER, H. K., Wilk, P., Cho, J., \& Greco, P. (2009). Empowerment, engagement and perceived effectiveness in nursing work environments: does experience matter? Journal of nursing management, 17(5), 636-646. https://doi.org/10.1111/j.1365-2834.2008.00907.x

Liden, R. C., Wayne, S. J., \& Sparrowe, R. T. (2000). An examination of the mediating role of psychological empowerment on the relations between the job, interpersonal relationships, and work outcomes. Journal of applied psychology, 85(3), 407. https://doi.org/10.1037/0021-9010.85.3.407

Macey, W. H., \& Schneider, B. (2008). The meaning of employee engagement. Industrial and organizational Psychology, 1(1), 3-30. https://doi.org/10.1111/j.1754-9434.2007.0002.x

MacLeod, D., \& Clarke, N. (2011). Engaging for success: enhancing performance through employee engagement, a report to Government.

Malik, M. E., Nawab, S., Naeem, B., \& Danish, R. Q. (2010). Job satisfaction and organizational commitment of university teachers in public sector of Pakistan. International journal of business and management, 5(6), 17. https://doi.org/10.5539/ijbm.v5n6p17

Mathieu, J. E., Gilson, L. L., \& Ruddy, T. M. (2006). Empowerment and team effectiveness: An empirical test of an integrated model. Journal of applied psychology, 91(1), 97. https://doi.org/10.1037/0021-9010.91.1.97

Maton, K. I., \& Salem, D. A. (1995). Organizational characteristics of empowering community settings: A multiple case study approach. American Journal of community psychology, 23(5), 631-656. 
https://doi.org/10.1007/BF02506985

Meyerson, G., \& Dewettinck, B. (2012). Effect of empowerment on employees performance. Advanced Research in Economic and Management Sciences, 2(1), 40-46.

Perkins, D. D., \& Zimmerman, M. A. (1995). Empowerment theory, research, and application. American journal of community psychology, 23(5), 569-579. https://doi.org/10.1007/BF02506982

Peterson, N. A., \& Zimmerman, M. A. (2004). Beyond the individual: Toward a nomological network of organizational empowerment. American journal of community psychology,34(1-2), 129-145. https://doi.org/10.1023/B:AJCP.0000040151.77047.58

Rich, B. L., Lepine, J. A., \& Crawford, E. R. (2010). Job engagement: Antecedents and effects on job performance. Academy of management journal, 53(3), 617-635. https://doi.org/10.5465/amj.2010.51468988

Schaufeli, W. B., \& Bakker, A. B. (2004). Job demands, job resources, and their relationship with burnout and engagement: A multi-sample study. Journal of Organizational Behavior: The International Journal of Industrial, Occupational and Organizational Psychology and Behavior, 25(3), 293-315. https://doi.org/10.1002/job.248

Sekaran, U., \& Bougie, R. (2016). Research methods for business: A skill building approach. John Wiley \& Sons.

Sharma, N., \& Singh, V. K. (2018). Psychological empowerment and employee engagement: Testing the mediating effects of constructive deviance in Indian IT Sector. International Journal of Human Capital and Information Technology Professionals (IJHCITP), 9(4), 44-55. https://doi.org/10.4018/IJHCITP.2018100103

Spreitzer, G. M. (1995). Psychological empowerment in the workplace: Dimensions, measurement, and validation. Academy of management Journal, 38(5), 1442-1465. https://doi.org/10.5465/256865

Sweem, S. L. (2009). Leveraging employee engagement through a talent management strategy: optimizing human capital through human resources and organization development strategy in a field study. Benedictine university.

Thamizhmanii, S., \& Hasan, S. (2010). A review on an employee empowerment in TQM practice. Journal of Achievements in Materials and Manufacturing Engineering, 39(2), 204-210.

Thomas, K. W., \& Velthouse, B. A. (1990). Cognitive elements of empowerment: An "interpretive" model of intrinsic task motivation. Academy of management review, 15(4), 666-681.

https://doi.org/10.5465/amr.1990.4310926

Wang, L., Law, K. S., Zhang, M. J., Li, Y. N., \& Liang, Y. (2019). It's mine! Psychological ownership of one's job explains positive and negative workplace outcomes of job engagement. Journal of Applied Psychology, 104(2), 229. https://doi.org/10.1037/ap10000337

Wefald, A. J. (2008). An examination of job engagement, transformational leadership, and related psychological constructs (Doctoral dissertation, Kansas State University).

Wilkinson, A. (1998). Empowerment: theory and practice. Personnel review. https://doi.org/10.1108/00483489810368549

Yin, N. (2018). The influencing outcomes of job engagement: an interpretation from the social exchange theory. International Journal of Productivity and Performance Management. https://doi.org/10.1108/IJPPM-03-2017-0054

\section{Copyrights}

Copyright for this article is retained by the author(s), with first publication rights granted to the journal.

This is an open-access article distributed under the terms and conditions of the Creative Commons Attribution license (http://creativecommons.org/licenses/by/4.0/). 